\title{
Universiteit
}

Leiden

The Netherlands

\section{Semantic context effects when naming Japanese kanji, but not}

\section{Chinese hànzì}

Verdonschot, R.G.; La Heij, W.; Schiller, N.O.

\section{Citation}

Verdonschot, R. G., La Heij, W., \& Schiller, N. O. (2010). Semantic context effects when naming Japanese kanji, but not Chinese hànzì. Cognition, 115, 512-518. Retrieved from https://hdl.handle.net/1887/15874

Version: $\quad$ Not Applicable (or Unknown)

License: $\quad$ Leiden University Non-exclusive license

Downloaded from: $\quad$ https://hdl.handle.net/1887/15874

Note: To cite this publication please use the final published version (if applicable). 
Brief article

\title{
Semantic context effects when naming Japanese kanji, but not Chinese hànzì
}

\author{
R.G. Verdonschot ${ }^{\mathrm{a}, \mathrm{b}, *}$, W. La Heij ${ }^{\mathrm{b}}$, N.O. Schiller ${ }^{\mathrm{a}, \mathrm{b}}$ \\ ${ }^{a}$ Leiden Institute for Brain and Cognition E Leiden University Centre for Linguistics, Leiden University, Leiden, The Netherlands \\ ${ }^{\mathrm{b}}$ Cognitive Psychology Unit, Leiden University, Leiden, The Netherlands
}

\section{A R T I C L E I N F O}

\section{Article history:}

Received 23 November 2009

Revised 10 February 2010

Accepted 1 March 2010

\section{Keywords:}

Semantic context effects

Reading aloud

Language production

Japanese kanji

Chinese hànzì

\begin{abstract}
A B S T R A C T
The process of reading aloud bare nouns in alphabetic languages is immune to semantic context effects from pictures. This is accounted for by assuming that words in alphabetic languages can be read aloud relatively fast through a sub-lexical grapheme-phoneme conversion (GPC) route or by a direct route from orthography to word form. We examined semantic context effects in a word-naming task in two languages with logographic scripts for which GPC cannot be applied: Japanese kanji and Chinese hànzì. We showed that reading aloud bare nouns is sensitive to semantically related context pictures in Japanese, but not in Chinese. The difference between these two languages is attributed to processing costs caused by multiple pronunciations for Japanese kanji.
\end{abstract}

(c) 2010 Elsevier B.V. All rights reserved.

\section{Introduction}

Models of word production distinguish various processing levels in object naming including conceptualization, retrieval of syntactic features, word-form encoding, and articulation (for overviews see e.g., Caramazza, 1997; Dell, 1986; Levelt, Roelofs, \& Meyer, 1999; Roelofs, 1992, 2008). Some of these models are based on results obtained with both the picture-word interference (PWI) paradigm (e.g. Caramazza \& Costa, 2000; Schriefers, Meyer, \& Levelt, 1990; Starreveld \& La Heij, 1995), in which pictures have to-be-named in the context of distractor words, and the "reversed" PWI paradigm in which words have to be read in the context of distractor pictures (e.g., Roelofs, 1992, 2006). An influential model of context effects in word

\footnotetext{
* Corresponding author. Address: Leiden Institute for Brain and Cognition (LIBC) \& Leiden University Centre for Linguistics (LUCL), Faculty of Humanities, Leiden University, P.O. Box 9555, NL-2300 RB Leiden, The Netherlands. Tel.: +31 6 43733255; fax: +31 715271650 .

E-mail address: r.verdonschot@hum.leidenuniv.nl (R.G. Verdonschot).
}

production and word reading, WEAVER++ (Indefrey \& Levelt, 2004; Levelt et al., 1999; Roelofs, 1992, 2006; Roelofs, Meyer, \& Levelt, 1996), assumes that in alphabetic languages a visually presented word can be processed along three different routes, depicted in Fig. 1 (adapted from Roelofs et al., 1996).

(1) A sub-lexical route from a graphemic representation to a phonemic representation (GPC), evidenced by non-words inducing reliable phonological facilitation in picture naming (Lupker, 1982).

(2) A route from orthographic to phonological wordform representations, evidenced by form-related distractor words speeding up picture naming (Koester \& Schiller, 2008; Zwitserlood, Bölte, \& Dohmes, 2000).

(3) A route from orthographic word representations to a word's lexical-syntactic representation, supported by semantic interference effects (e.g., Schriefers et al., 1990) and gender/determiner congruency effects (e.g., Schiller \& Caramazza, 2003) in picture naming. 


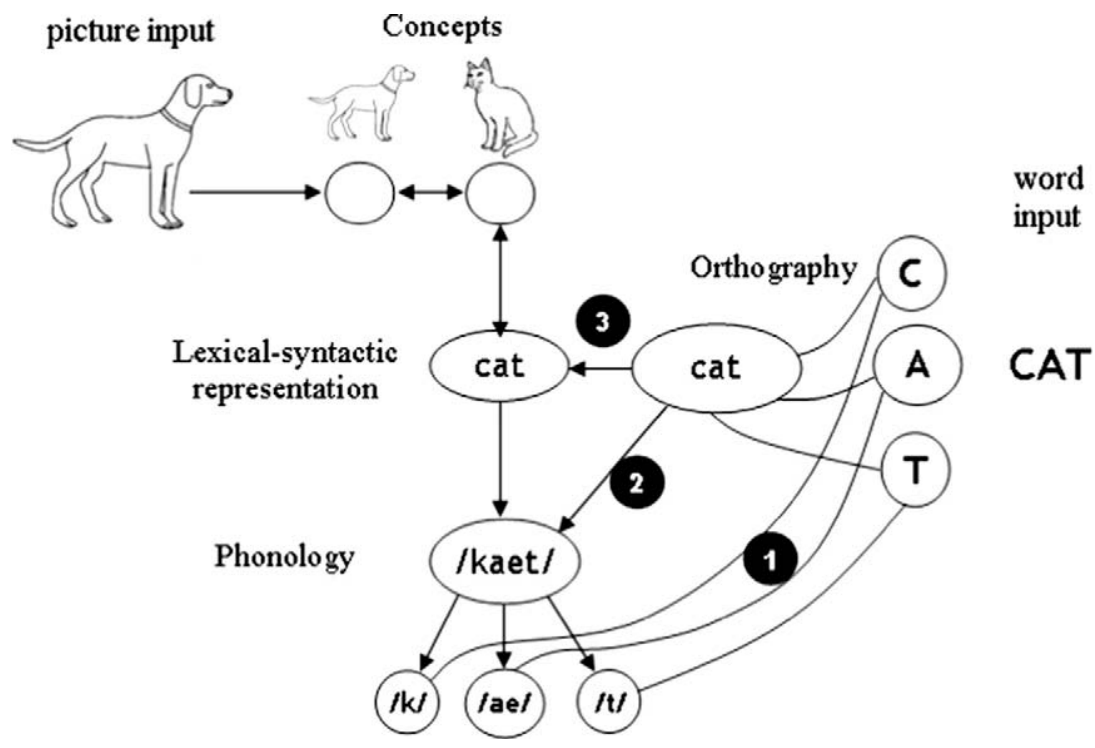

Fig. 1. Three processing routes of a visually presented word. Adapted from Roelofs, Meyer, \& Levelt (1996).

Although all three routes may be used, word-naming latencies are assumed to be determined by the fastest route, which is assumed to be Route 2 . This assumption is based on the observation that bare word reading is immune to semantic context effects (Glaser \& Düngelhoff, 1984; La Heij, Happel, \& Mulder, 1990; Roelofs, 2006; but see Roelofs, 2003). Semantic context effects in reading words are only observed when information at the lemma level is required. Roelofs (2006), for instance, reported that context pictures only induced semantic facilitation in a word reading task when Dutch participants were asked to respond to a single target word using a determiner-noun phrase (e.g., "de kat", the cat), requiring syntactic information at the lemma level (Route 3). This finding can be accounted for by assuming spreading of activation from the picture concept (DOG) to the word concept (CAT) and from there to the word's lexical-syntactic representation (see Fig. 1).

Most research on context effects in picture and word processing has been performed in alphabetic languages with scripts including sets of symbols (letters), which approximate sounds (and phonemes). However, other scripts such as logographic Chinese hànzì and Japanese kanji characters represent words or morphemes rather than individual sounds or phonemes. These different properties may lead to different results in PWI tasks and reversed PWI tasks.

Modern Chinese employs a logographic script called hànzì. Although some characters are iconic (like 山 / shan1/, 'mountain'), most characters are ideograms representing monosyllabic units with an elementary meaning (Chen, 1992; Taft \& Zhu, 1995). Many, but not all characters contain elements called radicals to indicate semantic group membership, mostly presented on the left side of the character (such as 木 'tree' in 松 'pine tree'), and radicals which are cues to the pronunciation of the character, mostly presented on the right side (such as 半 'half' in 伴 'partner' both pronounced /ban4/). Generally, Chinese words consist of two, but sometimes more characters that usually have a single pronunciation.

Modern Japanese, in contrast, employs three scripts, i.e. kanji, hiragana, and katakana. Kana characters, i.e. hiragana and katakana, were adapted from kanji to provide a means of representing native Japanese vocabulary, loanwords, proper names, and affixes. Historically, kanji were logographic characters imported from Chinese. In modern Japanese, they are used for representing words borrowed from Chinese, compounds of these words, and native Japanese vocabulary. There are two types of kanji pronunciations, i.e. $\mathrm{ON}$-readings, derived from the original Chinese pronunciation, and $K U N$-readings originating from the Japanese pronunciation. For instance, the kanji character 上 is without context pronounced as /ue/ but has different pronunciations when it occurs as the stem of a verb (上る/nobo.ru/, 'to climb' or 上げる/a.geru/, 'to give'); when it occurs together with other kanji or kana nouns or adjectives, it can be pronounced as /ue/, /uwa/ , /jyou/, or /kami/. More than 60\% of the 1945 basic kanji characters have different pronunciations in different contexts. This property of kanji might have processing consequences as shown by Kayamoto, Yamada, and Takashima (1998) who compared reading aloud latencies of high frequency kanji with only one reading, such as 脳 $/ \mathrm{nou}_{\text {on }} /$ 'brain' with high frequency kanji which have multiple readings, such as 街/ machi $_{\text {kun } / \text { or /gai }}$ on/ 'town'. Kanji with multiple readings were named slower, indicating that some processing cost was incurred compared to single reading kanji (Experiment 1). Such cost also emerged when mid-frequency kanji were used, except when alternative readings were weak (Experiment 2) which is in line with findings by Wydell, Butterworth, and Patterson (1995). 
To recapitulate, Chinese and Japanese logographs differ in that Japanese kanji often have more than one pronunciation whereas Chinese hànzì generally have a single pronunciation. This difference may be reflected in processing differences during reading aloud. Being logographic languages, both Chinese hànzì and Japanese kanji cannot be processed via a GPC route (Siok, Perfetti, Jin, \& Tan, 2004; Wydell et al., 1995). Within the model depicted in Fig. 1, this excludes Route 1. If words in both languages are read via Route 3 (involving lexical-syntactic representations), we may expect semantic facilitation effects of context pictures similar to those observed by Roelofs (2006) in determiner-noun phrase production in Dutch. If, however, Chinese hànzì and Japanese kanji are read via a direct route to the word-form level (Route 2 ), predictions are dependent on model-specific assumptions. In a discrete model like WEAVER++, in which activated lexical-syntactic representations do not automatically spread activation to word forms, reading via the word-form level should be unaffected by context pictures (Levelt et al., 1999). In contrast, in models assuming cascading of activation from lexicalsyntactic to word-form representations (e.g. Roelofs, 2008), context pictures may induce facilitation effects, provided that the activation from the conceptual level has enough time to affect processing at the word-form level. Given the processing costs due to resolving the correct pronunciation in Japanese kanji with multiple pronunciations (Kayamoto et al., 1998), discussed above, semantic facilitation may be larger when reading aloud Japanese kanji relative to Chinese hànzì.

To test these predictions we carried out a series of word-picture naming (i.e. reversed PWI) experiments using Japanese and Chinese stimuli in which to-be-named logograms were superimposed on semantically related or unrelated context pictures. To demonstrate that the potential absence of semantic effects in reading aloud is not due to the stimulus materials used, for both languages a standard picture-word interference (PWI) task (SOA $0 \mathrm{~ms}$ ), using the same Japanese and Chinese materials, were administered after the reading aloud task to the same participants. In both PWI tasks semantic interference effects are expected.

\section{Experiment: semantic context effects in Japanese and Chinese word reading}

\subsection{Method}

\subsubsection{Japanese participants}

Twenty-four native Japanese speakers (14 female; mean age: 31.5 years; $S D=8.1$ ) living in the Leiden and Amsterdam residential area in the Netherlands took part in the experiment. They had been living in the Netherlands on average for 4.5 years ( $S D=5.2$ ). The majority of the participants worked in a Japanese business-related environment and all participants reported to use kanji on a daily basis.

\subsubsection{Chinese participants}

Eighteen male college students from Dalian Maritime University (China) and two male non-university volunteers residing in Dalian took part in this experiment totalling 20 participants (mean age: 24 years; $S D=3.5$ ).

\subsubsection{Japanese stimuli}

Twenty target kanji having two or more readings were selected. Each kanji was paired with a semantically related and an unrelated context picture. Kanji - picture pairs were created such that semantically related and unrelated pictures occupied approximately the same screen area. It should be noted that the names of some of the context pictures are usually written in katakana (e.g. "spoon"), but since pictures enter the production system through the conceptual system (Caramazza, 1997; Levelt et al., 1999; Roelofs, 1992, 2006; see also Fig. 1), this is irrelevant for our current issue. See Appendix A and Fig. 2 for an overview of the Japanese and Chinese stimuli.
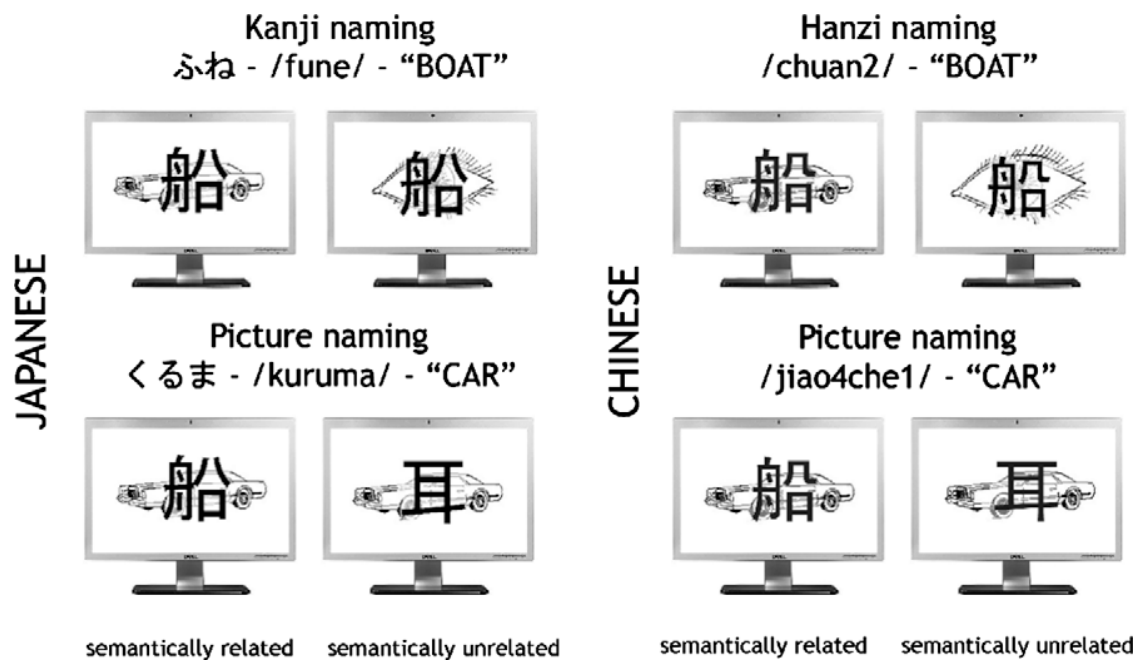

Fig. 2. Examples of experimental stimuli. 


\subsubsection{Chinese stimuli}

Twenty Chinese target hànzì stimuli were selected. All but two hànzì matched the Japanese in the sense that they also consisted of a single character. No target-context pairs were phonologically overlapping. There was no significant difference in mean target frequency (per million) between Japanese (366) and Chinese stimuli (201), $t(19)=1.72$, ns (taken from Yokoyama, Sasahara, Nozaki, \& Long, 1998, and Da, 2004, respectively).

\subsubsection{Reading aloud design}

For both the Japanese and Chinese part a $2 \times 2$ withinsubjects factorial design was implemented, with the factors SOA ( $0 \mathrm{~ms}$, i.e. picture and word presented simultaneously, or $-150 \mathrm{~ms}$, i.e. picture first) and Relatedness (semantically related or unrelated context picture). Each participant was subjected to 80 naming trials presented in two blocks (one block per SOA). For each participant, pseudo-random lists were constructed per block such that there were at least two intervening trials between phonologically or semantically related characters or pictures. Across participants, the order of blocks was counterbalanced. Each block was preceded by two warm-up trials (not included in the analysis).

\subsubsection{Reading aloud procedure}

Participants were seated approximately $60 \mathrm{~cm}$ from a 17 inch CRT computer screen in a quiet room at Leiden University (Japanese participants) or Dalian Maritime University (Chinese participants) and tested individually. Trials consisted of a fixation point $(1000 \mathrm{~ms})$ which was replaced by the kanji/hànzì - picture pair until participants responded or after maximally $2500 \mathrm{~ms}$. The experimenter recorded whether or not a response was accurate, followed by an inter trial interval of $500 \mathrm{~ms}$ before the next trial started. Naming latencies were measured from target onset using a voice-key. Participants were instructed to respond as fast as possible while avoiding errors.

\subsubsection{Picture naming procedure}

For the picture naming experiment, participants first saw the to-be-named pictures on the screen with the corresponding names printed underneath. Subsequently, pictures appeared without any distractor and participants were asked to name the pictures to verify whether they used the intended name. Then the experiment proper started. Trials consisted of a fixation point $(1000 \mathrm{~ms})$ followed and replaced by the picture - kanji/hànzì pair, which disappeared when participants responded or after

Table 1

Mean naming latencies (in milliseconds) and error rates (in \%) in the picture-naming task as a function of language and semantic relatedness.

\begin{tabular}{lrrrrrr}
\hline & \multicolumn{1}{l}{ Japanese } & & & \multicolumn{2}{l}{ Chinese } \\
\cline { 2 - 3 } \cline { 6 - 7 } & RTs (SD) & $\% E$ & & RTs (SD) & $\% E$ \\
\hline Related & $700(70.4)$ & 2.4 & & $784(88.1)$ & 2.9 \\
Unrelated & $678(64.4)$ & 3.4 & $750(92.3)$ & 2.5 \\
Effect (related-unrelated) & $22(43.3)$ & -1.0 & & $34(41.1)$ & 0.4 \\
\hline
\end{tabular}

maximally $2500 \mathrm{~ms}$. Following a response, the experimenter recorded whether or not the response was accurate before the next trial started.

\subsubsection{Results picture naming}

All analyses reported were carried out with participants $\left(F_{1}\right)$ and items $\left(F_{2}\right)$ as random variables. Naming latencies faster than $300 \mathrm{~ms}$ or exceeding $1500 \mathrm{~ms}$ were treated as outliers (Japanese: $2.7 \%$, Chinese: $1.8 \%$ of the data). An overview of the mean RTs and error rates is given in Table 1. A repeated measures analysis with one within-subjects factor (Relatedness) and one between-subjects factor (Language) was conducted. There was a main effect of Language, $\quad F_{1}(1,42)=11.64, \quad M S_{e}=11,460.04, \quad p<.001$; $F_{2}(1,38)=21.21, M S_{e}=6134.74, p<.001$, and Relatedness, $F_{1}(1,42)=18.58, M S_{e}=893.84, p<.001 ; F_{2}(1,38)=18.99$, $M S_{e}=890.77, p<.001$, but no interaction between Language and Relatedness, $F_{1}(1,42)=1.02, M S_{e}=893.84$, ns; $F_{2}(1,38)=1.02, M S_{e}=890.77$, ns, reflecting similar semantic interference effects for both languages. Planned comparisons demonstrated a $34 \mathrm{~ms}$ semantic interference effect for Chinese, $t_{1}(19)=3.70, S D=41.10, \quad p<.01$; $t_{2}(19)=3.67, S D=43.70, p<.01$, and a $22 \mathrm{~ms}$ semantic interference effect for Japanese, $t_{1}(23)=2.39, S D=43.30$, $p<.05 ; t_{2}(19)=2.46, S D=40.70, p<.05$. These results confirm that in both languages our selected stimuli were able to elicit semantic interference.

Interestingly, this well-known effect of distractor words on picture naming in alphabetic languages has not been investigated in depth with Japanese kanji and Chinese hànzì (but for Chinese see Zhang \& Weekes, 2009). Using a PWI task, Ishio (1990) failed to find semantic interference in the Japanese language. More recently, however, Iwasaki, Vinson, Vigliocco, Watanabe, and Arciuli (2008) reported robust semantic interference when naming actions in Japanese, and we demonstrate here that this is also the case for object naming in Japanese (and Chinese) using a standard PWI task.

\subsubsection{Results reading aloud}

RTs faster than $300 \mathrm{~ms}$ or exceeding $1500 \mathrm{~ms}$ were treated as outliers (Japanese: $1.5 \%$, Chinese: $1.1 \%$ of the data). An overview of the mean RTs and error rates is given in Table 2. One Japanese kanji, i.e. 肺 / hai/ 'lung' turned out to have only one pronunciation and was excluded from further analyses. A combined analysis of the two data sets revealed no main effect of Language, $F_{1}(1,42)<1$; $F_{2}(1,37)=1.75, M S_{e}=3860.51$, ns. The main effect of SOA was significant in the items analysis, but not in the participants analysis, $F_{1}(1,42)<1 ; F_{2}(1,37)=4.74, M S_{e}=491.27$, $p<.05$, reflecting (by items) that at SOA - 150 words were named $8 \mathrm{~ms}$ slower than at SOA $0 \mathrm{~ms}$. There was a significant $11 \mathrm{~ms}$ facilitation effect of Relatedness, $F_{1}(1,42)=$ 23.20, $M S_{e}=239.25, \quad p<.001 ; \quad F_{2}(1,37)=11.43, \quad M S_{e}=$ $424.64, p<.001$. Two interactions yielded significant effects, i.e. Language $\times$ SOA in the items analysis, $F_{1}(1,42)=$ 1.59, $M S_{e}=2544.97$, ns; $F_{2}(1,37)=8.33, M S_{e}=491.27$, $p<.01$, and Language $\times$ Relatedness, $F_{1}(1,42)=10.30$, $M S_{e}=239.25, \quad p<.01 ; \quad F_{2}(1,37)=5.51, \quad M S_{e}=424.64$, $p<.05$. To investigate these interactions in more detail, individual analyses were performed for both languages. 
Table 2

Mean naming latencies (in milliseconds) and error rates (in \%) in the reading aloud task as a function of SOA and semantic relatedness of the distractor picture.

\begin{tabular}{|c|c|c|c|c|c|c|c|c|}
\hline & \multicolumn{4}{|c|}{ Japanese Kanji Naming } & \multicolumn{4}{|c|}{ Chinese Hànzì Naming } \\
\hline & \multicolumn{2}{|l|}{ SOA - 150} & \multicolumn{2}{|l|}{ SOA 0} & \multicolumn{2}{|l|}{ SOA - 150} & \multicolumn{2}{|l|}{ SOA 0} \\
\hline & RTs (SD) & $\% E$ & RTs (SD) & $\% E$ & RTs (SD) & $\% E$ & RTs (SD) & $\% E$ \\
\hline Related & $531(51.1)$ & 1.0 & $519(65.7)$ & 0.8 & $519(59.2)$ & 1.5 & $525(61.4)$ & 3.0 \\
\hline Unrelated & $555(60.2)$ & 1.3 & 533 (74.9) & 1.3 & $526(60.3)$ & 2.5 & $525(67.3)$ & 1.3 \\
\hline Effect & $-24(25.0)$ & -0.3 & $-14(24.5)$ & -0.5 & -7 (18.9) & -1.0 & $0(14.5)$ & 1.7 \\
\hline
\end{tabular}

\subsubsection{Japanese results}

Mean RTs were submitted to a $2 \times 2$ repeated measures ANOVA with SOA and Relatedness as within-subject factors. There was no interaction between SOA and Relatedness. There was a main effect of SOA in the analysis by items but not by participants, $F_{1}(1,23)=2.85$, $M S_{e}=2392.36$, ns; $F_{2}(1,18)=12.61, M S_{e}=487.02, p<.01$, reflecting (by items) that at SOA - 150 words were named $18 \mathrm{~ms}$ slower than at SOA $0 \mathrm{~ms}$. Furthermore, there was a main effect of Relatedness, $F_{1}(1,23)=26.94, M S_{e}=314.55$, $p<.001 ; F_{2}(1,18)=22.84, M S_{e}=297.43, p<.001$. Kanji were named $19 \mathrm{~ms}$ faster in the context of a semantically related as compared to an unrelated picture. At SOA $0 \mathrm{~ms}$, there was a significant $14 \mathrm{~ms}$ semantic facilitation effect, $\quad t_{1}(23)=2.75, \quad S D=24.53, \quad p<.02 ; \quad t_{2}(18)=2.82$, $S D=21.50, p<.02$, and at SOA $-150 \mathrm{~ms}$, this effect was $24 \mathrm{~ms}, t_{1}(23)=4.67, S D=24.96, p<.001 ; t_{2}(18)=3.44$, $S D=30.30, p<.01$. As error rates were very low (overall $<1.1 \%$ ), no error analysis was performed.

\subsubsection{Chinese results}

The analysis was identical to the one performed on the Japanese data. The main effects of SOA (both $F s<1$ ) and Relatedness, $F_{1}(1,19)=1.92, M S_{e}=148.09$, ns; $F_{2}(1,19)<$ 1 , were not significant, and there was no interaction between SOA and Relatedness either, $F_{1}(1,19)=1.61$, $M S_{e}=135.87$, ns; $F_{2}(1,19)<1$. Error rates were very low (overall $<2.1 \%$ ) and therefore not analyzed.

\section{Discussion}

We reported four important empirical results in this study. First, a significant semantic interference effect induced by visually presented distractor words in Japanese picture naming. Second, an analogous semantic interference effect in Chinese picture naming. Third, a significant semantic facilitation effect induced by context pictures in Japanese word (kanji) naming at two SOAs $(-150 \mathrm{~ms}$ and $0 \mathrm{~ms}$ ). Fourth, the absence of such effects in Chinese word (hànzì) naming at the same SOAs.

The observation that naming Chinese hànzì does not show a semantic facilitation effect, despite the presence of a semantic interference effect in the corresponding picture-naming task, seems to rule out the hypothesis that words in this language are named via their lexical-syntactic representations. That is, Chinese hànzì are likely read via the direct route from orthography to phonology (Route
2 ). The presence of a semantic facilitation effect when reading Japanese kanji may be taken to suggest that our kanji characters are read via the lexical-semantic representation (Route 3). However, this interpretation is hard to reconcile with neuropsychological evidence indicating the use of a direct orthography to phonology route in reading kanji. Sasanuma, Sakuma, and Kitano (1992) and Nakamura et al. (1998) showed that the ability of patients with Alzheimer's dementia to comprehend kanji deteriorated over time, while their ability to read kanji aloud was retained. More recently, Fushimi et al. (2003) reported a Japanese surface-dyslexic patient whose reading performance is best explained by assuming: (a) an intact orthography-to-phonology route (Route 2 in Fig. 1) and (b) a reduction of activation arriving from semantics.

Given these considerations, the most parsimonious interpretation of our findings is that the kanji characters used in our experiment activate multiple phonological representations (via Route 2 in Fig. 1), which induces a processing delay that allows activation from the semantic system to affect response latencies. In contrast, in reading Chinese hànzì only one phonological representation is activated and selected, allowing no time for activation from semantics to speed up this process. The observation that Japanese kanji words do not take more reading aloud time than Chinese hànzì cannot be taken as evidence against this proposal, as the kanji and hànzì words used in our experiments differed both in form and pronunciation.

In conclusion, although we cannot fully exclude the possibility that kanji characters are read via a lexicalsyntactic route, our data are most parsimoniously accounted for by assuming that: (a) logographic scripts, like alphabetic scripts, are read via a direct route from orthography to word-form representations and (b) this route is susceptible to semantic context effects when multiple mappings between orthography and word-form are possible.

\section{Acknowledgements}

The authors would like to thank Vincent Marion for his technical assistance, Haoran Zhao for running the Chinese version of the experiment, and Katsuo Tamaoka and Sachiko Kiyama as well as three anonymous reviewers for their valuable comments on an earlier version of this manuscript. 


\section{Appendix A}

\begin{tabular}{|c|c|c|c|c|c|}
\hline Japanese kanji target & Chinese hànzì target & Japanese related picture & Chinese related picture & Japanese unrelated picture & Chinese unrelated picture \\
\hline 犬 (dog; inu/ken) & 狗 (dog; gou3) & Cat (neko) & Horse (ma3) & Harp (haapu) & Harp (shu4qin2) \\
\hline 牛 (cow; ushi/gyuu) & 牛 (cow; niu2) & Sheep (hitsuji) & Sheep (yang2) & Bed (beddo) & Axe (fu3zi) \\
\hline 雲 (cloud; kumo/un) & 云 (cloud; yun2) & Sun (taiyou) & Sun (tai4yang2) & Chicken (niwatori) & Chicken (ji1) \\
\hline 足 (leg; ashi/soku) & 脚 (leg; jiao3) & Arm (ude) & Arm (shou3bi4) & Cup (koppu) & Cup (bei1) \\
\hline 空 (window; mado/sou) & 窗 (window; chuang1) & Door (doa) & Door (men2) & Trousers (zubon) & Trousers (ku4zi) \\
\hline 木 (tree; ki/moku) & 树 (tree; shu4) & Flower (hana) & Flower (hua1) & Brain (nou) & Brain (nao3) \\
\hline 耳 (ear; mimi/ji) & 耳 (ear; er3) & Eye (me) & Eye (yan3jing1) & Car (kuruma) & Car (jiao4che1) \\
\hline 弓 (bow; yumi/kyuu) & 弓 (bow; gong1) & Axe (ono) & Axe (fu3zi) & Spoon (supuun) & Spoon (shao2) \\
\hline 箸 (chopsticks; hashi/cho) & 刀 (knife; dao1) & Spoon (supuun) & Spoon (shao2) & Axe (ono) & Bed (chuang2) \\
\hline 豚 (pig; buta/ton) & 猪 (pig; zhu1) & Chicken (niwatori) & Chicken (ji1) & Sun (taiyou) & Sun (tai4yang2) \\
\hline 海 (sea; umi/kai) & 海 (sea; hai3) & Mountain (yama) & Mountain $(\operatorname{shan} 1)$ & Church (kyoukai) & Church (jiao4tang2) \\
\hline 皿 (plate; sara/bei) & 盘 (plate; pan2) & Cup (koppu) & Cup (bei1) & Arm (ude) & Arm (shou3bi4) \\
\hline 船 (boat; fune/sen) & 船 (boat; chuan2) & Car (kuruma) & Car (jiao4che1) & Eye (me) & Eye (yan3jing1) \\
\hline 剣 (sword; ken/tsurugi) & 剑 (sword; jian4) & Pistol (pisutoru) & Pistol (shou3qiang1) & Bolt (boruto) & Hammer (chui2zi) \\
\hline 机 (desk; tsukue/ki) & 桌 (desk; zhuo1) & Bed (beddo) & Bed (chuang2) & Sheep (hitsuji) & Sheep (yang2) \\
\hline 笛 (flute; fue/teki) & 家 (flute; di2) & Harp (haapu) & Harp (shu4qin2) & Cat (neko) & Horse (ma3) \\
\hline 家 (house; ie/ka) & 房 (house; fang2) & Church (kyoukai) & Church (jiao4tang2) & Mountain (yama) & Mountain (shan1) \\
\hline 肺 (lung; hai) & 肺 (lung; fei4) & Brain (nou) & Brain (nao3) & Flower (hana) & Flower (hua1) \\
\hline 釘 (nail; kugi/tei) & 锯 (saw; ju4) & Bolt (boruto) & Hammer (chui2zi) & Pistol (pisutoru) & Pistol (shou3qiang1) \\
\hline 靴 (shoes; kutsu/ka) & 鞋 (shoes; xie2) & Trousers (zubon) & Trousers (ku4zi) & Door (doa) & Door (men2) \\
\hline
\end{tabular}

Note: For the Japanese kanji targets the left pronunciation is the pronunciation for the kanji when standing alone, and all subjects in our experiments used these pronunciations without exception. Only the kanji 剣 can standalone be pronounced both as $/ \mathrm{ken}_{\mathrm{on}} /$ or $/$ tsurugi $\mathrm{k}_{\mathrm{kun}} /$, however, our participants were consistent in naming this kanji $/ \mathrm{ken}_{\mathrm{on}} /$ as this is the modern term. It was furthermore checked whether excluding from the analyses four Japanese kanji which turned out to have rather infrequent alternative readings (i.e., 箸, 皿, 釘 and 靴) would yield different results; this turned out not to be the case. The Chinese targets matched the Japanese targets with two exceptions: (1) the symbol for 'chopsticks' (筷/kuai4/ or in Japanese 箸/hashi/) which was substituted with 'knife' (刀/dao1/) as Chinese readers would find it quite unusual to pronounce 筷 without the nominal suffix 子 (筷子/kuai4zi/) and (2) the Japanese symbol for 'nail' 釘 (/kugi/) which was replaced in Chinese by 'saw' (锯/ ju4/) for the same reason. Although the pictures enter the production process through the conceptual system (Roelofs, 1992, 2006; Caramazza, 1997; Levelt et al., 1999), we nevertheless decided to change the semantically related picture 'cat' (猫) into 'horse' (狗) since in Chinese (not Japanese 犬) its semantic radical would have overlapped with 'dog' (狗). Finally, for the Chinese pictures 'bolt' was replaced by 'hammer' to yield a categorically related context picture for the target 'saw'. 


\section{References}

Caramazza, A. (1997). How many levels of processing are there in lexical access? Cognitive Neuropsychology, 14, 177-208.

Caramazza, A., \& Costa, A. (2000). The semantic interference effect in the picture-word interference paradigm: Does the response set matter? Cognition, 75, B51-B64.

Chen, H. C. (1992). Reading comprehension in Chinese: Implication for character reading times. In H. C. Chen \& O. J. L. Tzeng (Eds.), Language processing in Chinese (pp. 175-205). North-Holland: Amsterdam.

Da, J. (2004). A corpus-based study of character and bigram frequencies in Chinese e-texts and its implications for Chinese language instruction. The studies on the theory and methodology of the digitalized Chinese teaching to foreigners. In Z. Pu, T. Xie, \& J. Xu (Eds.), Proceedings of the fourth international conference on new technologies in teaching and learning Chinese (pp. 501-511). Beijing: Tsinghua University Press.

Dell, G. S. (1986). A spreading-activation theory of retrieval in sentence production. Psychological Review, 93, 283-321.

Fushimi, T., Komori, K., Ikeda, M., Patterson, K., Ijuin, M., \& Tanabe, H. (2003). Surface dyslexia in a Japanese patient with semantic dementia: Evidence for similarity-based orthography-to-phonology translation. Neuropsychologia, 41, 1644-1658.

Glaser, W. R., \& Düngelhoff, F. J. (1984). The time course of picture-word interference. Journal of Experimental Psychology: Human Perception and Performance, 10, 640-654.

Indefrey, P., \& Levelt, W. J. M. (2004). The spatial and temporal signatures of word production components. Cognition, 92, 101-144.

Ishio, A. (1990). Auditory-visual Stroop interference in picture-word processing. The Japanese Journal of Psychology, 61, 329-335.

Iwasaki, N., Vinson, D. P., Vigliocco, G., Watanabe, M., \& Arciuli, J. (2008) Naming actions in Japanese: Effects of semantic similarity and grammatical class. Language and Cognitive Processes, 23, 889-930.

Kayamoto, Y., Yamada, J., \& Takashima, H. (1998). The consistency of multiple-pronunciation effects in reading: The case of Japanese logographs. Journal of Psycholinguistic Research, 27, 619-637.

Koester, D., \& Schiller, N. O. (2008). Morphological priming in overt language production: Electrophysiological evidence from Dutch. Neurolmage, 42, 1622-1630.

La Heij, W., Happel, B., \& Mulder, M. (1990). Components of Stroop-like interference in word reading. Acta Psychologica, 73, 115-129.

Levelt, W. J. M., Roelofs, A., \& Meyer, A. S. (1999). A theory of lexical access in speech production. Behavioral and Brain Sciences, 22, 1-75.

Lupker, S. J. (1982). The role of phonetic and orthographic similarity in picture-word interference. Canadian Journal of Psychology, 36, 349-367.

Nakamura, K., Meguro, K., Yamazaki, H., Ishizaki, J., Saito, H., Saito, N., Shimada, M., Yamaguchi, S., Shimada, Y., \& Yamadori, A. (1998). Kanji predominant alexia in advanced Alzheimer's disease. Acta Neurologica Scandinavia, 97, 237-243.
Roelofs, A. (1992). A spreading-activation theory of lemma retrieval in speaking. Cognition, 42, 107-142.

Roelofs, A. (2003). Goal-referenced selection of verbal action: Modeling attentional control in the Stroop task. Psychological Review, 110, $88-125$.

Roelofs, A. (2006). Context effects of pictures and words in naming objects, reading words, and generating simple phrases. Quarterly Journal of Experimental Psychology, 59, 1764-1784.

Roelofs, A. (2008). Tracing attention and the activation flow in spoken word planning using eye movements. Journal of Experimental Psychology: Learning, Memory, and Cognition, 34, 353-368.

Roelofs, A., Meyer, A. S., \& Levelt, W. J. M. (1996). Interaction between semantic and orthographic factors in conceptually driven naming: Comment on Starreveld and La Heij (1995). Journal of Experimental Psychology: Learning, Memory, and Cognition, 22, 246-251.

Sasanuma, S., Sakuma, N., \& Kitano, K. (1992). Reading kanji without semantics: Evidence from a longitudinal study of dementia. Cognitive Neuropsychology, 9, 465-486.

Schiller, N. O., \& Caramazza, A. (2003). Grammatical feature selection in noun phrase production: Evidence from German and Dutch. Journal of Memory and Language, 48, 169-194.

Schriefers, H., Meyer, A. S., \& Levelt, W. J. M. (1990). Exploring the time course of lexical access in speech production: Picture-word interference studies. Journal of Memory and Language, 29, 86-102.

Siok, W. T., Perfetti, C. A., Jin, Z., \& Tan, L. H. (2004). Biological abnormality of impaired reading is constrained by culture. Nature, 431, 71-76.

Starreveld, P. A., \& La Heij, W. (1995). Semantic interference, orthographic facilitation and their interaction in naming tasks. Journal of Experimental Psychology: Learning, Memory, and Cognition, 21, 686-698.

Taft, M., \& Zhu, X. (1995). The representation of bound morphemes in the lexicon: A Chinese study. In L. Feldman (Ed.), Morphological aspects of language processing (pp. 293-315). Hillsdale, NJ: Lawrence Erlbaum.

Wydell, T. N., Butterworth, B. L., \& Patterson, K. E. (1995). The inconsistency of consistency effects in reading: Are there consistency effects in Kanji? Journal of Experimental Psychology: Learning, Memory and Cognition, 21, 1155-1168.

Yokoyama, S., Sasahara, H., Nozaki, H., \& Long, E. (1998). Shinbun denshi media no kanji: Asahi shimbun no CD-ROM-ni yoru kanji hindo hyoo. Tokyo: Sanseido [Japanese kanji in the newspaper media: Kanji frequency index from the Asahi newspaper on CD-ROM].

Zhang, Q. F., \& Weekes, B. S. (2009). Orthographic facilitation effects on spoken word production: Evidence from Chinese. Language and Cognitive Processes, 24, 1082-1096.

Zwitserlood, P., Bölte, J., \& Dohmes, P. (2000). Morphological effects on speech production: Evidence from picture naming. Language and Cognitive Processes, 15, 563-591. 